\title{
Development of Reverse Transcription Semi-nested PCR Primer Pairs for the Specific and Highly Sensitive Detection of Human Aichivirus A1
}

\author{
Siwon Lee ${ }^{*}$ and Kyu Bong Cho ${ }^{\dagger ; *}$ \\ Department of Biomedical Laboratory Science, Shinhan University, Uijeongbu 11644, Korea
}

\begin{abstract}
Human Aichivirus A1 (HuAiV-A1) is a waterborne human pathogenic virus classified as Picornaviridae and Kobuvirus. In this study, we developed a method that can detect about 35 minutes faster with the same detection sensitivity level than the previously reported HuAiV-A1 diagnostic RT-PCR primer. The RT-PCR primer sets developed in this study are capable of detecting HuAiV-A1 at a level of about 100 ag and formed $563 \mathrm{bp}$ amplification product. In addition, the RT-nested PCR method was able to amplify $410 \mathrm{bp}$ using the RT-PCR product as a template. The detection sensitivity of our method was 10 times higher than the method with the highest detection sensitivity to date. Therefore, the detection method of HuAiV-A1 developed in this study is expected to be used in the water environment in which a small amount of virus exists. Also, this detection method is expected to be used as HuAiV-A1 diagnostic technology in both clinical and non-clinical field.
\end{abstract}

Key Words: HuAiV-A1, Human aichivirus A1, Kobuvirus, RT-nested PCR, Waterborn human pathogenic virus

\section{서 론}

사람 아이치바이러스[Human Aichivirus 1; HuAiV-A1]는 1989년 일본 아이치현 비 세균성 위장염 환자의 대변 검 체에서 최초로 보고되었다(Reuter al., 2009). HuAiV-A1의 입자는 약 $30 \mathrm{~nm}$ 로 표면이 둥글고 울퉁불퉁하며, 분류학 적으로 바이러스 group IV, Picornaviridae, Kobuvirus (Aichivirus A)에 속한다. 미국 국립생물정보센터에 따르면, 전체 핵산의 길이는 약 8,251 nucleotide (nt)로, 5' non-translated region (NTR) $712 \mathrm{nt}, 3^{\prime}$ NTR $240 \mathrm{nt}$ 및 중앙의 7,302 nt는 polyprotein을 암호화하며, 약 2,433개 아미노산을 지시한 다. HuAiV-A1은 인체 병원성 바이러스로 사람에게 감염 시 설사, 복통, 구토, 구역질, 발열 등의 증상이 나타난다 (Khamrin and Maneekarn, 2014; Khamrin et al., 2011). 현재까
지 보고되고 있는 HuAiV-A1은 설사 환자에게 약 0 4.1\% 수준으로 검출되고 있어 다른 수인성 장바이러스에 비해 상대적으로 낮은 출현빈도를 보이며(Saikruang et al., 2014) 단독 감염보다는 다른 바이러스 등의 병원체와 혼합 감염 형태로 주로 나타나고 있다.

또한 개발도상국과 선진국에 관계없이 아시아, 유럽, 남미, 북미 등 전세계적으로 발생되고 있으며, 생굴, 젓갈 등 수산물, 상수원수, 강 등 환경에도 넓은 범위로 오염 이 되어 있는 것으로 보고되고 있다(Yamashita et al., 2000; Oh et al., 2006; Guyader et al., 2008; Pham, 2011). 따라서 국내 에서도 이러한 문제점을 직시하여 국립환경과학원 등 국 가기관을 중심으로 HuAiV-A1 등과 같은 미 규제 병원체 에 대한 모니터링을 위한 연구사업, 표준검사법 개발 등 의 대응이 이루어지고 있다. 현재 수인성 바이러스의 표 준검사법으로 시료에서 추출한 총 핵산에서 conventional

Received: September 2, 2019 / Revised: October 18, 2019 / Accepted: November 25, 2019

* Professor.

${ }^{\dagger}$ Corresponding author: Kyu Bong Cho. Department of Biomedical Laboratory Science, Shinhan University, Uijeongbu 11644, Korea. Tel: +82-31-870-3712, Fax: +82-31-870-3719, e-mail: kbcho@shinhan.ac.kr

(C) The Korean Society for Biomedical Laboratory Sciences. All rights reserved.

(C) This is an Open Access article distributed under the terms of the Creative Commons Attribution Non-Commercial License (http://creativecommons.org/licenses/by-nc/3.0/) which permits unrestricted non-commercial use, distribution, and reproduction in any medium, provided the original work is properly cited. 
polymerase chain reaction (C-PCR)으로 바이러스의 특정 단 편을 증폭하는 방법이 활용되고 있다. C-PCR은 real-time qPCR과 등온증폭법(loop mediated isothermal amplification; LAMP)에 비해 오랜 기간 연구되어 안정성이 입증되었고 따라서, 넓은 범위의 사용자를 가지고 있으며, 아울러 결 과 산물을 추가 반응 없이 sequencing 할 수 있는 장점이 있어 임상 및 비 임상 시료에서 병원체를 진단하는 표준 화 방법으로 활용이 적합하다(Yamashita et al., 2003; Reuter et al., 2009; Santos et al., 2015). 그러나 HuAiV-A1 진단용 C-PCR 기술은 다수의 연구자들에 의한 많은 보고가 있 지만 속도, 검출 민감도 등에 대한 비교 연구는 부족하 다. 특히 물 환경 시료의 경우 미량 오염 및 다수의 PCR 저해 물질이 포함되어 있어 높은 특이성 및 검출 민감도 가 요구되고 있다. 또한 기존의 연구들은 PCR 반응 조건 이 달라 같은 시료에서 추출한 총 핵산에서 Rotavirus-A, Norovirus 등의 다른 수인성 바이러스들과 동시에 PCR을 수행할 수 없어 다량의 분석이 필요한 검사기관에서 활용 에 많은 애로가 따랐다. 따라서 이러한 문제점을 해결하 기 위한 검출 민감도 및 특이성이 높고 현장에서의 활용 성이 확보된 새로운 진단 기술의 개발이 필요한 실정이다.

따라서 본 연구에서는 위 조건에 부합하는 reverse transcription nested (RT-nested) PCR 기반의 HuAiV-A1 진단용 $\mathrm{PCR}$ 프라이머 조합을 개발하고, 기존에 보고된 C-PCR 방 법들과 민감도, 특이성, 현장 활용성 등이 우수한 C-PCR 시스템을 개발하고자 하였다.

\section{재료 및 방법}

\section{특이적 PCR 프라이머 제작 및 표준균주 수집}

HuAiV-A1 특이적 프라이머 제작을 위하여 DNAMAN software package version 6.0 (Lynnon Biosoft, Quebec, Canada) 를 사용하였다. 탐색 조건은 HuAiV-A1 NCBI accession NC_001918 2,740 3,918 (1,179 nt)를 기준으로 하였으며, 검사자의 편의성을 위해 기존 수인성 바이러스의 PCR 조 건으로 활용되고 있는 annealing 온도 $51 \sim 59^{\circ} \mathrm{C}$ (최적 $55^{\circ} \mathrm{C}$ ) 로 하였다(NIER, 2016). HuAiV-A1에 특이적 결합을 할 것 으로 추정되는 정방향 및 역방향 프라이머들을 대상으로 Oligo Calculator version 3.27를 통해 프라이머의 특이성, 스 스로 부착되어 효율이 저하될 수 있는지에 대한 가능성 등을 분석하여 최종 후보 프라이머 조합들을 제작하였다.

특이적 반응에 사용할 $\mathrm{HuAiV-A1}$ 주형 핵산은 $\mathrm{NC}_{-}$001918.1 VP3-VP1 [2,740 3,918 (1,179 nt)]을 마크로젠(Seoul,
Korea)에 의뢰하여 linear 상태로 gene을 합성하였다. 비 특 이적 반응에 활용할 참고 바이러스주 핵산[RNA, DNA or cDNA; (Rotavirus A, Parechovirus A, Norovirus GII, Coronavirus, Enterovirus-68, Enterovirus-71, Coxakievirus-A6, Coxakievirus-B1, Coxakievirus-B5, non-enteric Adenovirus $\mathrm{C}$ 및 enteric Adenovirus 41)]와 linear type gene 합성 [Aichivirus-B (NC_004421; 4,571 5,370), Aichivirus-C (NC_011829; 4,417 5,216), Parvovirus-B19 (NC_000883.2; 3,001 5,000), Hepatitisvirus-A (K02990.1; 2,014 4,013) 및 Sapovirus (KP298674.1; 4,440 6,439)]을 수집하였다. RNA 형태로 수집된 것은 ReverTra Ace- $\alpha$-® (TOYOBO, Osaka, Japan)으로 cDNA로 합성하여 사용하였다. 한편, HuAiV-A1 참고 프라이머의 반응을 위 해 3CD [NC_001918.1; 6,038 8,011 (1,974 nt)]를 linear type 으로 gene 합성하였다.

\section{프라이머 선발}

HuAiV-A1에 특이적으로 증폭이 가능할 것으로 추정되 는 PCR 프라이머 조합을 이용하여, 특이적, 비 특이적 및 검출 민감도 분석을 수행하였다. 특이적 반응은 주형 핵 산인 HuAiV-A1 핵산을 $100 \mathrm{fg} / \mu \mathrm{L}$ 농도로 사용하여 구성 된 PCR 프라이머 조합에 대한 특이적 밴드의 형성 여부 를 확인한 후, 반응이 강하고 증폭산물의 크기가 적합한 조합을 선발하였다. 특이적 반응에서 선발된 PCR 프라이 머 조합들을 이용하여 참고 바이러스주 15 종에 대한 비 특이적 반응을 검정하였다. 이후 참고 바이러스주들에 대 하여 핵산에 반응이 나타나지 않은 PCR 프라이머 조합들 을 HuAiV-A1 진단에 적합하다고 추정하였다. 또한 특이 적 및 비 특이적 시험에서 선발된 PCR 프라이머 조합들 을 대상으로 검출 민감도를 분석하였다. HuAiV-A1 핵산 $1 \mathrm{ng} / \mu \mathrm{L}$ 기준으로 10 배 단계 희석하여 $10^{-4}(100 \mathrm{fg} / \mu \mathrm{L})$ $10^{-9}(1 \mathrm{ag} / \mathrm{\mu L})$ 의 농도로 희석된 HuAiV-A1 핵산들을 주형 으로 민감도 분석을 시행하였다. 본 연구에서 사용되는 주형은 linear type으로 합성된 DNA였지만, 실제 시료에 서는 total RNA 추출 후 RT-PCR로 반응해야 하는 것을 감안하여 one step RT-PCR을 수행하였다. RT-PCR 조성은 AccuPower ${ }^{\circledR}$ RT/PCR PreMix (Bioneer, Daejeon, Korea), PCR 프라이머(정방향 및 역방향) 각각 $25 \mathrm{pmol}$ 농도로 $2 \mu \mathrm{L}$, 주형 핵산 $1 \mu \mathrm{L}$ 및 멸균증류수 $17 \mu \mathrm{L}$ 로 하여 총 $20 \mu \mathrm{L}$ 로 반응하였다. RT-PCR 반응 조건은 $42^{\circ} \mathrm{C}$ 에서 60 분 동안 역 전사, $95^{\circ} \mathrm{C}$ 에서 5 분 동안 초기 변성단계를 거쳐 $95^{\circ} \mathrm{C}$ 에서 45 초간 변성, $55^{\circ} \mathrm{C}$ 에서 1 분간 결합, $72^{\circ} \mathrm{C}$ 에서 1 분간 신장 하는 단계를 35 회 반복하였으며 그 후 $72^{\circ} \mathrm{C}$ 에서 5 분간 최 


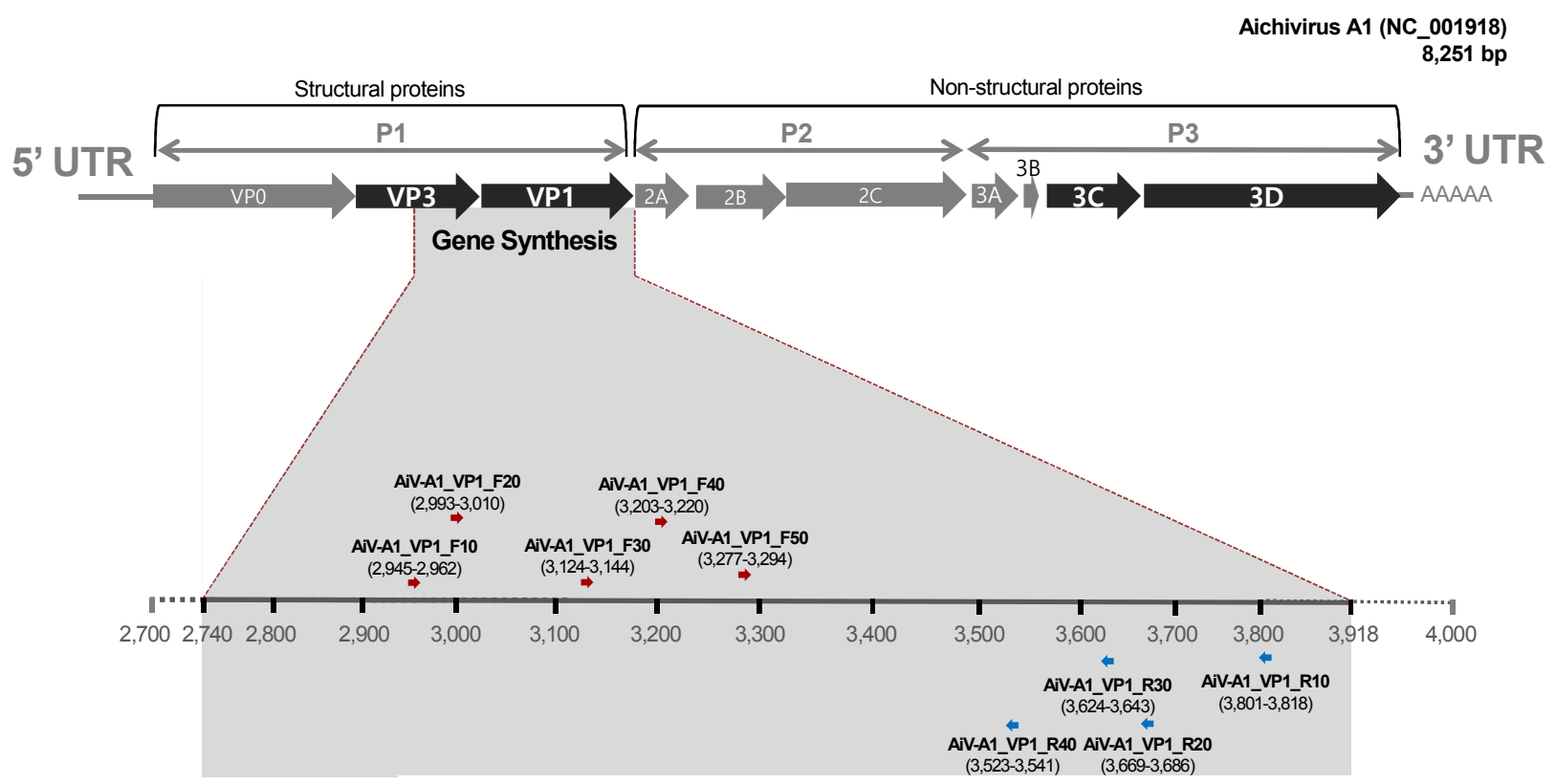

Fig. 1. Specific RT-nested PCR primers map for the detection of Human Aichivirus A1 (HuAiV-A1).

종 신장하였다(NIER, 2016).

한편, nested PCR 프라이머 조합을 선발하기 위해 최종 선발된 RT-PCR 프라이머 조합에서 nested PCR 증폭이 가능한 조합을 설계 및 제작하였다. RT-PCR을 통해 생성 된 산물을 주형으로 검출 민감도 시험을 위한 최종 nested $\mathrm{PCR}$ 프라이머 조합을 선발하였다. Nested PCR의 조성은 AccuPower ${ }^{\circledR}$ HotStart PCR PreMix (Bioneer), PCR 프라이머 (정방향 및 역방향) 각각 $25 \mathrm{pmol}$ 농도로 $2 \mu \mathrm{L}$, 주형 DNA (RT-PCR 산물) $1 \mu \mathrm{L}$ 및 멸균증류수 $17 \mu \mathrm{L}$ 로 하여 총 $20 \mu \mathrm{L}$ 로 하였다. Nested PCR 조건은 RT-PCR 과정 중 역전 사 과정을 제외하고 동일하게 하였다. RT-PCR 및 nested PCR 산물들은 $1.2 \%$ agarose gel을 사용하여 $100 \mathrm{~V}$ 에서 30 분 동안 전기영동 후 gel documentation system (Bio Rad, California, USA)에서 확인하였다.

\section{기존 시험법 비교}

기존 시험법과 검출 민감도를 비교하기 위하여 HuAiV$\mathrm{A} 1$ 의 VP3-1 부분을 합성한 $1,179 \mathrm{nt}$ 와 $3 \mathrm{CD}$ 부분을 합성한 1,974 nt를 혼합한 칵테일을 제작하였다. Oligo Calculator version 3.27 서버에 각 염기서열을 입력한 후 분자량을 계산한 결과 합성한 $3 \mathrm{CD}$ 부분이 VP3-1 부분의 약 1.68 배 인 것을 고려하여 혼합 시 $\mathrm{VP} 3-1$ 과 $3 \mathrm{CD}$ 의 비율을 1.68 : 1.00 으로 조절하여 copy 수를 맞추었다. 혼합한 칵테일을
10 배 단계 희석하였으며, 이것들을 주형으로 본 연구에서 선발한 RT-nested PCR 프라이머 조합 및 기존 conventional $\mathrm{PCR}$ 프라이머 조합들의 검출 민감도를 분석하였다. 또한, 조건 별 반응 시간 비교를 위하여 역전사 과정은 KIT의 프로토콜에 따라 30 분 1시간 수준으로 상이하지만 모두 60 분으로 통합 계산하였으며, PCR이 시작된 후 종료 시 점까지의 시간을 비교하였다.

\section{결 과}

\section{프라이머 제작}

HuAiV-A1에 특이적이고, 스스로 결합되는(self annealing) 등의 문제가 나타나지 않는 9 개의 PCR 프라이머(정방향 5 개 및 역방향 4 개)가 탐색되었다(Fig. 1, Table 1). PCR 프 라이머를 조합하여 PCR 증폭이 가능한 20개 조합을 구 성하였으며, 약 248 874 base pair (bp)의 길이었다(Data not shown).

\section{RT-PCR 프라이머 선발}

총 20개 PCR 프라이머 조합을 대상으로 HuAiV-A1에 대한 특이적 반응을 분석한 결과, 20 개 중 15 개 조합(조합 $\# 02, \# 03, \# 04, \# 06, \# 07, \# 08, \# 10, \# 11, \# 12, \# 14, \# 15, \# 16, \# 18$, \#19 및 \#20)에서 특이적 반응이 나타났으며 밴드의 강도, 
Table 1. Information of RT-PCR and nested PCR primer sets for the detection of Human Aichivirus 1 (HuAiV-A1)

\begin{tabular}{|c|c|c|c|c|c|c|}
\hline \multirow{2}{*}{ \# } & \multirow{2}{*}{$\begin{array}{l}\text { PCR } \\
\text { type }\end{array}$} & \multirow{2}{*}{$\begin{array}{l}\text { Target } \\
\text { gene }\end{array}$} & \multicolumn{2}{|r|}{ Primer } & \multirow{2}{*}{$\begin{array}{l}\text { Product } \\
\text { size (nt) }\end{array}$} & \multirow{2}{*}{ References } \\
\hline & & & Name & Sequence $\left(5^{\prime}-3^{\prime}\right)$ & & \\
\hline \multirow{9}{*}{$\begin{array}{l}\mathrm{PCR} \\
\text { primer } \\
\text { pairs } \\
\# 01 \sim 20\end{array}$} & \multirow{9}{*}{$\begin{array}{l}\text { RT-PCR \& } \\
\text { nested PCR }\end{array}$} & \multirow{9}{*}{ VP3-VP1 } & HuAiV-A1_VP3-1_F10 & ATCTCCGCAGGTGAATCC & \multirow{9}{*}{$265 \sim 874$} & \multirow{9}{*}{ This study } \\
\hline & & & HuAiV-A1_VP3-1_F20 & СТСАСТТСССАААСССТC & & \\
\hline & & & HuAiV-A1_VP3-1_F30 & CACCAAACTGGAAAACTTCTT & & \\
\hline & & & HuAiV-A1_VP3-1_F40 & GCYRACGAAGGCACAATC & & \\
\hline & & & HuAiV-A1_VP3-1_F50 & GATGCTRTCGTGCTTCAC & & \\
\hline & & & HuAiV-A1_VP3-1_R10 & GCACGATGTAGACCCGRT & & \\
\hline & & & HuAiV-A1_VP3-1_R20 & GGACCCAGGCTTTGAAGT & & \\
\hline & & & HuAiV-A1_VP3-1_R30 & CTGGAAGTCRARGGGRATRG & & \\
\hline & & & HuAiV-A1_VP3-1_R40 & GTCCTCCCAWCCRAAGTAY & & \\
\hline \multirow{2}{*}{ Ref. 01} & \multirow{2}{*}{ RT-PCR } & \multirow{2}{*}{ VP1 } & Yip-VP1_F & ТCTTCTCСТTCTACCGCTTG & \multirow{2}{*}{357} & \multirow{2}{*}{$\begin{array}{l}\text { Yip et al. } \\
\text { (2014) }\end{array}$} \\
\hline & & & Yip-VP1_R & GAGGTGTAGGGGATGGAGAA & & \\
\hline \multirow{4}{*}{ Ref. 02} & \multirow{4}{*}{$\begin{array}{l}\text { RT-nested } \\
\text { PCR }\end{array}$} & \multirow{4}{*}{ VP3-VP1 } & KBP1 & СТСYТTСАТСТСYМАМТССТАСТGG & \multirow{2}{*}{1,245} & \multirow{4}{*}{$\begin{array}{l}\text { Yamashita } \\
\text { et al. (2014) }\end{array}$} \\
\hline & & & KBN1 & AAGTGGGTRCAGTTGTTGG & & \\
\hline & & & $\mathrm{KbP1P}$ & CAGCCMCGCACCACYTTCSASTAC & \multirow{2}{*}{453} & \\
\hline & & & $\mathrm{KbP} 1 \mathrm{~N}$ & GAAGTAKGARGTGGGRATRGCAGA & & \\
\hline \multirow{4}{*}{ Ref. 03} & \multirow{4}{*}{$\begin{array}{l}\text { RT-nested } \\
\text { PCR }\end{array}$} & \multirow{4}{*}{ VP3-VP1 } & AiV-VP3-F1 & CACACCGCCCCTGCGTCRGCCCTCGT & 721 & \\
\hline & & & AiV-VP1-R1 & GAGAGCTGGAAGTCRAAGGG & 121 & \\
\hline & & & AiV-VP1-F2 & CTCGATGCRCCMCAAGACACCGG & 505 & \\
\hline & & & AiV-VP1-R2 & CCTGACCAGTCCTCCCAWCCGAAGTA & $30 J$ & Lodder \\
\hline & & & AiV-VP3-F1 & CACACCGCCCCTGCGTCRGCCCTCGT & 721 & et al. (2013) \\
\hline Pef 04 & RT-nested & VP2 VP1 & AiV-VP1-R1 & GAGAGCTGGAAGTCRAAGGG & 121 & \\
\hline Ne1. 07 & PCR & $810-811$ & AiV-VP1-F3 & GTGCTTCACRTACATCGCYGCGG & 230 & \\
\hline & & & AiV-VP1-R2 & CCTGACCAGTCCTCCCAWCCGAAGTA & 25 & \\
\hline & & & C94b & GACTTCCCCGGAGTCGTCGTCT & & Khamrin and \\
\hline 1.t. & & S & AiMP-R & GCRGAGAATCCRCTCGTRCC & 100 & $(2014)$ \\
\hline & & & 6261 (RT-PCR) & ACACTCCCACCTCCCGCCAGTA & 510 & \\
\hline $\operatorname{Ref} 06$ & RT-nested & $3 C D$ & 6779 (RT-PCR) & GGAAGAGCTGGGTGTCAAGA & (1) & Saikruang \\
\hline 1.1. 00 & PCR & $\pi$ & C94b (Nested PCR) & GACTTCCCCGGAGTCGTCGTCT & ר? & et al. (2014) \\
\hline & & & 246k (Nested PCR) & GACATCCGGTTGACGTTGAC & $22 J$ & \\
\hline Ref 07 & RTPCR & $3 C D$ & C94b & GACTTCCCCGGAGTCGTCGTCT & 158 & Pham (2011) \\
\hline N1. & $3 x-10$ & J & AiMP-R & GCRGAGAATCCRCTCGTRCC & 100 & Н \\
\hline $\operatorname{Ref} 08$ & RT-PCR & $3 \mathrm{CD}$ & $10 f(7357)$ & GATGCTCCTCGGTGGTCTCA & 631 & Santos et al. \\
\hline Ker. 00 & $101-10$ & J & 10r (7987) & GTCGGGGTCCATCACAGGGT & (1) & (2015) \\
\hline $\operatorname{Ref} 09$ & RT_PCR & $3 C D$ & UNIV-kobu-F & TGGAYTACAARTGTTTTGATGC & 216 & Reuter et al. \\
\hline Kel. U9 & КI-PCK & $\pi D$ & UNIV-kobu-R & ATGTTGTTRATGATGGTGTTGA & 210 & $(2009)$ \\
\hline & & & 6261 (RT-PCR) & ACACTCCCACCTCCCGCCAGTA & 519 & \\
\hline Ref 10 & RT-nested & $3 \mathrm{CD}$ & 6779 (RT-PCR) & GGAAGAGCTGGGTGTCAAGA & & Alcalá et al. \\
\hline אला. 10 & PCR & So & $\mathrm{AiF} 2(6283 \sim 6305)$ & CAAGGACTTGCGGCGCTTCATCG & 412 & $(2010)$ \\
\hline & & & AiR2b (6672 6694) & GCACCCYTCYCCCGCCTACGGTG & 412 & \\
\hline
\end{tabular}


증폭한 PCR 산물의 길이, 증폭이 된 위치 등을 고려하여 14 개 중 5개 조합(\#02, \#06, \#08,\#10 및 \#18)을 선발하였다 (Fig. 2). 특이적 반응에서 선발된 5개의 PCR 프라이머 조 합을 대상으로 15 개 참고 바이러스주 핵산에 비 특이적 반응을 분석한 결과, 5 개 $\mathrm{PCR}$ 프라이머 조합 모두에서 비

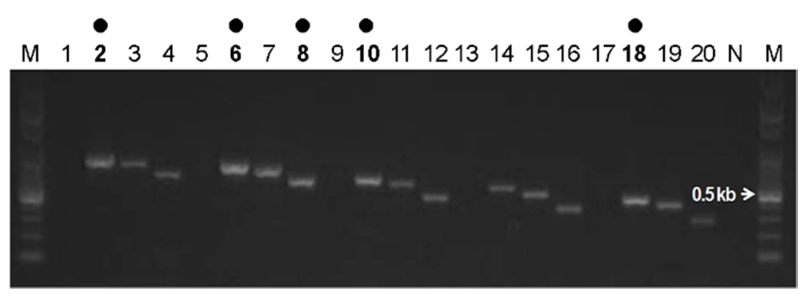

Fig. 2. Specific reaction of RT-PCR primer pairs for the detecting HuAiV-A1. Lane M, 100 bp Ladder marker; lane number, primer sets number (1 20); N, negative control; dot, selective primer sets.
특이적 반응이 나타나지 않아(Fig. 3), 선발된 5개 PCR 프 라이머 조합은 HuAiV-A1를 특이적으로 진단할 수 있을 것으로 추정되었다. 또한, 5 개의 PCR 프라이머 조합을 대 상으로 검출 민감도를 분석한 결과, 4개 조합(\#02, \#06, \#08 및 \#18)에서는 $1 \mathrm{fg}$ 수준인 $10^{-6}$ 까지 밴드가 형성되었으며, 조합 \#10의 경우 $100 \mathrm{ag}$ 수준인 $10^{-7}$ 까지 검출 민감도가 나타나, HuAiV-A1를 진단하기에 적합한 RT-PCR 프라이 머 조합으로 선발되었다. 최종 선발된 $\mathrm{HuAiV-A1} \mathrm{진단용}$ RT-PCR 프라이머 조합은 HuAiV-1의 VP3-1에 대한 프라 이머 $\mathrm{F} 30$ 과 $\mathrm{R} 20$ 조합으로 $563 \mathrm{bp}$ 의 $\mathrm{PCR}$ 산물을 증폭할 수 있었다(Fig. 4).

\section{Nested PCR 프라이머 선발}

RT-PCR 프라이머 조합 \#10 (F30/R20)의 산물을 주형으 로 nested PCR 증폭이 가능한 2개 프라이머 조합[\#10-1

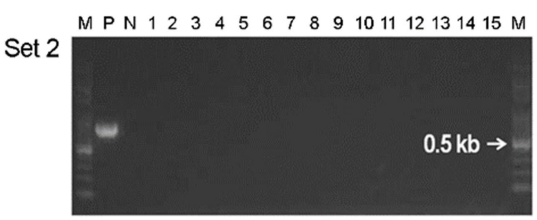

Set 8

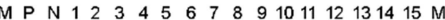

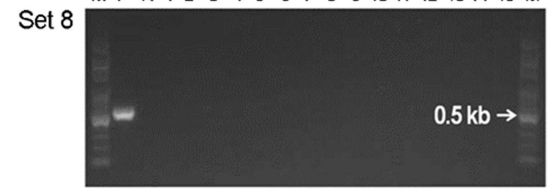

Set 18

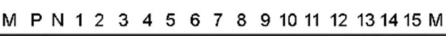

$0.5 \mathrm{~kb} \rightarrow$

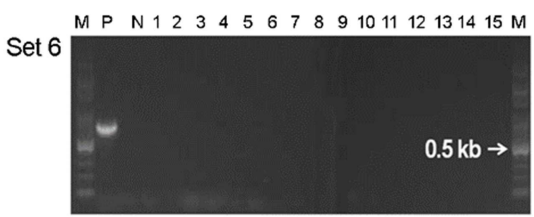

Set 10
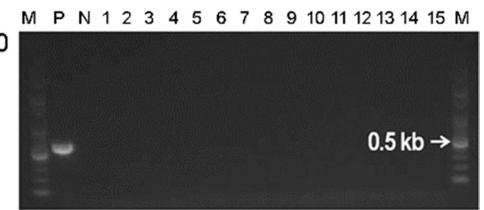

Fig. 3. Non-specific reaction of five RT-PCR primer pairs. Lane M, $100 \mathrm{bp}$ Ladder marker; P, positive control; N, negative control; lane number, reference viruses [1, Aichivirus-B; 2, AichivirusC; 3, Rotavirus A; 4, Parechovirus A; 5, Norovirus GII; 6, Coronavirus 229E; 7, Enterovirus-68; 8, Enterovirus-71; 9 Coxakievirus-A6; 10, Coxakievirus-B1; 11, Coxakievirus-B5; 12, non-enteric Adenovirus C; 13 , enteric Adenovirus 41; 14, Hepatitisvirus-A; 15, Sapovirus].

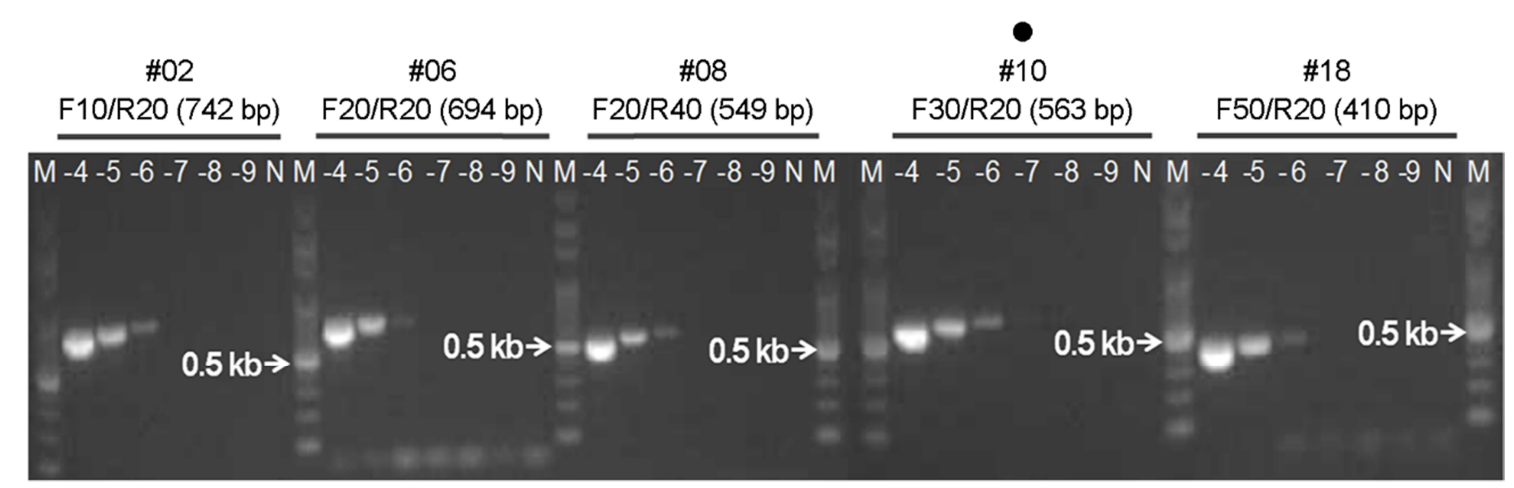

Fig. 4. Sensitivity tests of five specific RT-PCR primer pairs. Lane M, $100 \mathrm{bp}$ Ladder marker; lane number, diluted rates from $1 \mathrm{ng} / \mu \mathrm{L}$; $\mathrm{N}$, negative control; dot, selective primer sets. 
Table 2. Comparison of reaction time and sensitivity between this study and previously reported RT-nested PCR primer sets for the detection of HuAiV-A1

\begin{tabular}{|c|c|c|c|c|}
\hline \multicolumn{2}{|c|}{ Primer set } & Reaction time (min) & Sensitivity & Remark \\
\hline \multirow{2}{*}{ This study } & RT-PCR & 175 & 100 atto gram & \\
\hline & Nested PCR ${ }^{*}$ & 290 & 10 atto gram & \\
\hline Ref. primer set \#01 & RT-PCR & 227 & 100 atto gram & \\
\hline \multirow{2}{*}{ Ref. primer set \#02 } & \multirow{2}{*}{ RT-PCR } & 155 & 100 femto gram & \\
\hline & & 219 & 1 femto gram & Non-specific reaction \\
\hline \multirow{2}{*}{ Ref. primer set \#03 } & RT-PCR & 142 & 10 femto gram & \\
\hline & Nested PCR ${ }^{*}$ & 214 & 10 femto gram & Non-specific reaction \\
\hline \multirow{2}{*}{ Ref. primer set \#04 } & RT-PCR & 142 & 10 femto gram & \\
\hline & Nested PCR ${ }^{*}$ & 214 & 1 femto gram & Non-specific reaction \\
\hline Ref. primer set \#05 & RT-PCR & 203 & 1 femto gram & \\
\hline \multirow{2}{*}{ Ref. primer set \#06 } & RT-PCR & 157 & 1 femto gram & \\
\hline & Nested PCR ${ }^{*}$ & 254 & 100 atto gram & Non-specific reaction \\
\hline Ref. primer set \#07 & RT-PCR & 193 & 100 atto gram & Non-specific reaction \\
\hline Ref. primer set \#08 & RT-PCR & 160 & 1 femto gram & \\
\hline Ref. primer set \#09 & RT-PCR & 193 & 1 femto gram & Non-specific reaction \\
\hline \multirow{2}{*}{ Ref. primer set \#10 } & RT-PCR & 160 & 1 femto gram & Non-specific reaction \\
\hline & Nested PCR ${ }^{*}$ & 257 & 100 atto gram & Non-specific reaction \\
\hline
\end{tabular}

(F40/R30; $441 \mathrm{bp)}$ 및 \#10-2 (F50/R20; 410 bp)]이 설계되었 다. 검출 민감도 분석 결과, 모두 $10 \mathrm{ag}$ 수준인 $10^{-8}$ 까지 동일한 검출 민감도가 분석되었으며, 이 중 참고 바이러 스에 비 특이적 반응이 검정된 \#10-2 (F50/R20; 410 bp)를 최종 선발하였다(Fig. 5).

\section{기존 시험법 비교}

기존 보고된 HuAiV-A1 진단을 위한 RT-PCR 또는 RTnested PCR 10개를 대상(Table 2)으로 검출 민감도를 분석 한 결과, RT-PCR에서는 Yip et al. (2014) 및 Pham (2011)이 보고한 방법에서는 약 $100 \mathrm{ag}\left(10^{-7}\right)$ 의 검출 민감도가 나 타났으며, 나머지 방법들은 약 $100 \mathrm{fg}\left(10^{-4}\right)$ 부터 $1 \mathrm{fg}\left(10^{-6}\right)$ 수준으로 나타났다. 그러나 기존 방법은 각각 227 분 및 193 분의 반응 시간이 소요되었으나, 이번에 개발한 방법 은 175 분으로 기존 반응 시간을 약 18 52분 단축시켰다. 또한 RT-nested PCR에서 최고의 검출 민감도가 나타난 Saikruang et al. (2014) 및 Alcalá et al. (2010)가 보고한 기존 방법이 각각 254 분 및 257 분인데 반해, 이번 연구에서 개 발한 nested PCR은 RT-PCR을 포함 및 중간 전기영동 반 응 시간을 제외하면 총 290분으로 기존 RT-nested PCR 반 응 시간에 비해 약 33 36분 정도 반응 시간이 길었다. 그

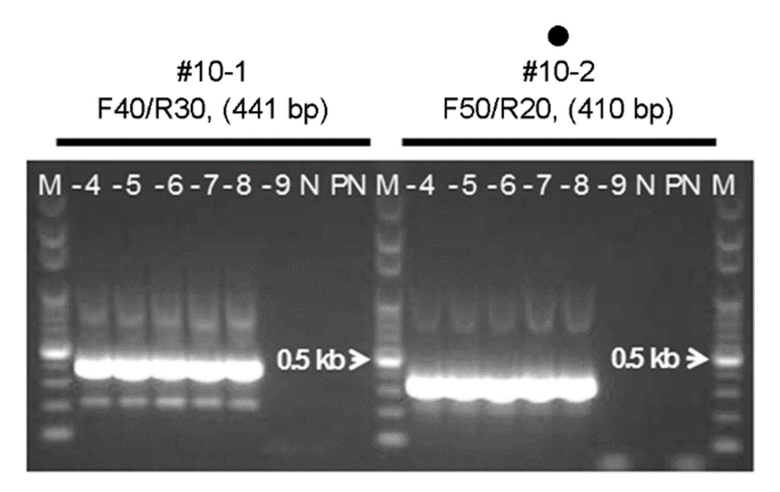

Fig. 5. Selection of nested PCR primer pair for the detecting HuAiV-A1. Lane M, 100 bp Ladder marker; lane number, diluted rates from $1 \mathrm{ng} / \mu \mathrm{L} ; \mathrm{N}$, negative control PN, PCR-negative control; dot, selective primer sets

러나 기존의 두 방법은 약 $100 \mathrm{ag}$ 수준의 검출 민감도가 나타난 반면, 본 연구에서 개발한 방법은 $10 \mathrm{ag}$ 의 검출 민 감도를 나타내 기존에 비해 약 10 배 좋은 민감도가 나타 났다. 그러나 반응에 비 특이적 밴드도 일부가 형성되었 다. 한편, 다른 RT-nested PCR 방법들의 검출 민감도는 약 $1 \sim 10 \mathrm{fg}$ 수준으로 나타나 이번 연구에서 개발한 RT-nested PCR 방법에 비해 약 $10 \sim 1,000$ 배 낮은 민감도를 나타냈 
다(Fig. 5).

\section{고 찰}

본 연구에서는 $\mathrm{HuAiV}-\mathrm{A} 1$ 의 보다 효과적인 진단용 RTnested PCR 프라이머 조합을 개발하고자 하였으며 현재 $\mathrm{HuAiV}-\mathrm{A} 1$ 을 비롯한 수인성 바이러스 진단을 위한 기존의 방법으로는 ELISA 등을 이용한 효소면역측정법이 있었 으나, PCR 검사법에 비해 약 1,000 배 수준의 낮은 검출 민감도, 낮은 특이성, 판독 오류 등이 나타날 수 있으며, 특히 환경과 같이 병원체에 대한 오염도 밀도가 상대적으 로 낮은 경우 검출 민감도가 진단 기술에 중요한 척도가 됨에 따라 최근에는 특이적 핵산을 증폭하는 분자 진단 기술이 많이 활용되고 있다(Cho, 2018). 따라서 환경부 등 국가기관에서는 C-PCR, real-time qPCR, LAMP 등 분자기 반의 진단 기술 중에서도 안정성, 활용성 등을 고려하여 타 검사법에 비해 C-PCR을 기반으로 한 표준검사 기술 을 주로 활용하고 있다(NIER, 2016).

한편, 기존에 보고된 $\mathrm{HuAiV-A1}$ 의 진단용 C-PCR 프라이 머 조합들은 환경 등 비 임상 시료에서는 $3 \mathrm{CD}$ gene을 임 상에서는 주로 VP3-VP1 gene을 대상으로 하고 있다(Table 1). 그러나 특정 시료에서 바이러스 특이적 핵산을 진단 하는데 있어 임상과 비 임상에 따른 시료의 구분은 큰 의미는 없어 보인다. 오히려 최근 정부의 범부처 수인성 식품매개 바이러스 협의체에서는 Norovirus 검사법 통합 이 논의되고 있는 등 각 시료 별로 바이러스의 지역 별 발생현황, 거동 특성 등의 다양한 연구를 하기 위해서는 향후 임상, 환경, 해양수산, 농축산 등에서 바이러스 검사 시 전 처리 방법을 제외하고는 병원체 분석법의 통합 추 진이 논의되고 있는 실정이다. 이번 연구에서 개발한 RT$\mathrm{PCR}$ 프라이머 조합은 현재까지 보고되고 있는 RT-PCR 방법 중 최고 수준인 100 atogram(최초 합성된 농도를 $1 \mathrm{ng} / \mu \mathrm{L}$ 으로 한 것을 기준으로 $10^{-7}$ ) 수준의 검출 민감도 가 나타났으며, 동급 수준을 나타낸 검사법에 비해 검사 시간을 평균 약 35 분 단축시켰다. 따라서 본 검사법은 임 상, 식품, 해양수산 등의 시료에서 $\mathrm{HuAiV-A1}$ 진단에 적합 할 것으로 사료된다. 한편, nested $\mathrm{PCR}$ 의 경우 기존의 시 간(전기영동 제외 약 4 시간 15 분) 보다 총 검사 시간이 약 35 분 길어진 4 시간 50 분이 소요되었다. 그러나 음용 및 비음용 지하수와 농업용수 등의 시료에서는 검출 민감도 가 중요하다. 이번 연구에서 개발한 nested $\mathrm{PCR}$ 은 기존 방법 중 우수한 검출 민감도를 보였으므로 환경 시료 등
에서의 활용이 적합할 것으로 보인다. 그러나 향후 실질 적 시료에서의 활용성 등 많은 사례가 검증되어야 할 것 으로 생각된다. 본 연구에서 개발된 RT-nested PCR 프라 이머 조합은 임상과 비 임상에서 HuAiV-A1 진단에 효율 적인 기술로 활용될 것으로 기대된다.

\section{ACKNOWLEDGEMENT}

This work was supported by the Technology development Program (S2661713) funded by the Ministry of SMEs and Startups (MSS, Korea).

\section{CONFLICT OF INTEREST}

No potential conflict of interest relevant to this article was reported.

\section{REFERENCES}

Alcalá A, Vizzi E, Rodriguez-Diaz J, Zambrano JL, Betancourt W, Liprandi F. Molecular detection and characterization of Aichi viruses in sewage-polluted waters of Venezuela. Appl Environ Microbiol. 2010. 76: 4113-4115.

Cho KB. Development of nested PCR primer set for the specific and highly sensitive detection of human Parvovirus B19. Biomed. Sci. Lett. 2018. 24: 390-397.

Guyader FSL, Le Saux JC, Ambert-Balay K, Krol J, Serais O, Parnaudeau S, Giraudon H, Delmas G, Pommepuy M, Pothier P, Atmar RL. Aichi virus, Norovirus, Astrovirus, Enterovirus, and Rotavirus involved in clinical cases from a french oysterrelated gastroenteritis outbreak. J Clin Microbiol. 2008. 46: 4011-4017.

Khamrin P, Maneekarn N. Epidemiology of human and animal kobuviruses. Virus Dis. 2014. 25: 195-200.

Khamrin P, Okame M, Thongprachum A, Nantachit N, Nishimura S, Okitsu S, Maneekarn N, Ushijima H. A single-tube multiplex PCR for rapid detection in feces of 10 viruses causing diarrhea J Virol Methods. 2011. 173: 390-393.

Lodder WJ, Rutjes SA, Takumi K, de Roda Husman AM. Aichi virus in sewage and surface water, the Netherlands. Emerg Infect Dis. 2013. 19: 1222-1230.

NIER. Development and verification of genetically diagnostic method for the detection of non-regulated viruses from water environment (I). 2016. pp. 1-21. NIER, Incheon, Korea.

Oh DY, Silva PA, Hauroeder B, Diedrich S, Cardoso DDP, Schreier 
E. Molecular characterization of the first Aichi viruses isolated in Europe and in South America. Arch Virol. 2006. 151: 1199 $-1206$.

Pham NT. Study on Aichi virus, parechovirus, and bocavirus detected in children with acute gastroenteritis in Japan, Bangladesh, Thailand, Vietnam, and Sri Lanka. Tokyo University. 2011. Masters dissertation.

Reuter G, Boldizsar A, Papp G, Pankovics P. Detection of Aichi virus shedding in a child with enteric and extraintestinal symptoms in Hungary. Arch Virol. 2009. 154: 1529-1532.

Saikruang W, Khamrin P, Suantai B, Ushijima H, Maneekarn N. Molecular detection and characterization of Aichivirus A in adult patients with diarrhea in Thailand. J Med Virol. 2014. 86: 983-987.

Santos N, Mendes GS, Silva RC, Pena GA, Rojas M, Amorim AR, Lima DP. Salivirus and aichivirus A infections in children with gastroenteritis in Brazil. Clin Microbiol Infect. 2015. 21: 799.e1-799.e3.

Yamashita T, Adachi H, Hirose E, Nakamura N, Ito M, Yasui Y, Kobayashi S, Minagawa H. Molecular detection and nucleotide sequence analysis of a new Aichi virus closely related to canine kobuvirus in sewage samples. J Med Microbiol. 2014. 63:
715-720.

Yamashita T, Ito M, Kabashima Y, Tsuzuki H, Fujiura A, Sakae K. Isolation and characterization of a new species of kobuvirus associated with cattle. J Gen Virol. 2003. 84: 3069-3077.

Yamashita T, Sugiyama M, Tsuzuki H, Sakae K, Suzuki Y, Miyazaki Y. Application of a reverse transcription-PCR for identification and differentiation of Aichi virus, a new member of the picornavirus family associated with gastroenteritis in humans. J Clin Microbiol. 2000. 38: 2955-2961.

Yip CCY, Lo KL, Que TL, Lee RA, Chan KH, Yuen KY, Woo PCY, Lau SKP. Epidemiology of human parechovirus, Aichi virus and salivirus in fecal samples from hospitalized children with gastroenteritis in Hong Kong. Virol J. 2014. 11: 182.

https://doi.org/10.15616/BSL.2019.25.4.331

Cite this article as: Lee $S$, Cho KB. Development of Reverse Transcription Semi-nested PCR Primer Pairs for the Specific and Highly Sensitive Detection of Human Aichivirus A1. Biomedical Science Letters. 2019. 25: 331-338. 